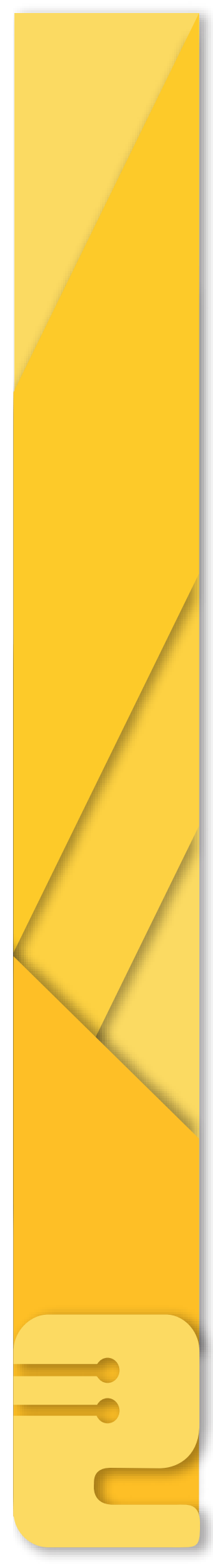

\title{
EDITORIAL
}

\section{LOS DRONES: UNA ALTERNATIVA PARA EL DESARROLLO DE LA INGENIERÍA EN COLOMBIA}

Una de las últimas tendencias en ingeniería con enfoque social y resolución de problemas en diferentes contextos, son los dispositivos conocidos como Drones -palabra inglesa que significa "zángano -", los cuales han tenido diferentes usos como dispositivos no tripulados y de costo razonable que permiten aplicaciones civiles en los más diversos campos, desde las clásica cartografía y fotografía aérea, pasando por la búsqueda de personas desaparecidas, control de calidad de cultivos, supervisión de terrenos, alarmas contra incendios, etc.

Cada vez los avances en la ingeniería hacen de estos dispositivos, con su diminutivo tamaño, su alta disponibilidad y sin riesgo para las personas, una herramienta y alternativa para acceder a lugares difíciles, tener un rápido despliegue, un bajo consumo de combustible, y numerosas ventajas más, lo cual permite que las industrias, empresas e instituciones generen mayor competitividad, eficacia y calidad de la información suministrada desde el aire a un costo coherente y racional.

Colombia cuenta con 1,1 millones de kilómetros cuadrados de territorio continental y una topografía desafiante, lo cual pone de manifiesto a las universidades colombianas en generar proyectos productivos e innovativos de un modelo de negocios para la toma de fotografías aéreas y la recolección de datos del terreno que apoyen la puesta en marcha de grandes proyectos de corte ingenieril. El reto de atravesar selvas y bordear los ríos en ciertas zonas del territorio nacional de difícil acceso por las condiciones geográficas y la presencia de grupos al margen de la ley fue asumido hace tres años por Dymaxion, una compañía bogotana dedicada al ensamblaje y operación de aviones no tripulados.

De otra parte, es pertinente señalar que el análisis económico muestra que el costo de un Dron oscila entre los 1000 y 450000 dólares, lo cual depende de las diferentes etapas del diseño en ingeniería para lograr datos que generan modelos digitales de terreno y superficie y ortofotografías o imágenes en las que se combinan el detalle de las fotos aéreas con los de un plano. "La importancia de este tipo de tecnología para Colombia radica en minimizar los tiempos de desarrollo de los proyectos de ingeniería y facilitar el acceso a lugares en donde es difícil llegar con personal en campo", explicó Guevara, Director de Dymaxion.

A través de innpulsa y por intermedio de Dymaxion, se ha dado a conocer la importancia y la puesta en marcha de estos dispositivos en los procesos de ingeniería, tanto así que lograron que una firma de hidrocarburos se interesara en sus servicios. 
En 2013, nnpulsa invitó a grandes empresas de los sectores petrolero y minero interesadas en abrir sus puertas para resolver sus desafíos con aportes por terceros. De estos resultados se pude señalar que cada vez son más altos los estándares de seguridad, procesamiento de datos, avance en la parte electrónica, el ensamblaje de los aviones no tripulados de tipo liviano y compuesto por fibra de carbono, fibra de vidrio, plástico reforzado y aluminio provenientes de China, Alemania, Australia y Estados Unidos; y que el sector universitario debe ahondar para la fabricación de estos aparatos, realizar los análisis y estudios pertinentes para coadyuvar a empresas como Dymaxion.

Ahora bien, actualmente, en la planta de la Corporación de la Industria Aeronáutica Colombiana (CIAC), un grupo de especialistas avanza en la puesta a punto del primer avión no tripulado, tipo Dron, que se fabrica en el país. Otro gran desarrollo y avance es el convenio generado entre cIAc e Indumil, y en la misma mediada, se encuentra la modernización de los Tucano T-27 de fabricación brasilera, entre otros. De igual forma, es oportuno señalar que el Ingeniero electrónico José Gregorio Morales se ha dedicado a construir drones para distintos propósitos comerciales, y cada fin de semana prueba algo distinto de software o hardware para ellos. A mediano plazo, lo que busca este ingeniero es convertir su pasión por los hobbies en un negocio en el que sea posible desarrollar drones a la medida, de modo que presten distintos servicios.

Finalmente, desde la Corporación Universitaria Minuto de Dios, específicamente desde la Facultad de Ingeniería se vienen adelantando diversos trabajos académicos como el desarrollo de cursos sobre ésta temática, la publicación de artículos en la REVISTA INVENTUM y la construcción de contenidos curriculares para el programa de Maestría en Agrónica. 